\title{
Cardiovascular Risk Management With Liaison Critical Path in Japan: Its Effects on Implementation of Evidence-Based Prevention in Practice
}

\author{
Morihiro Matsuda a, b, c, d, Manami Akizuki ${ }^{\mathrm{a}}$, Orie Nishimoto ${ }^{\mathrm{a}}$, Kei Nakamoto \\ Hirohiko Nishiyama ${ }^{\text {, Ritsu Tamura }}{ }^{\text {, }}$ Toshiharu Kawamoto ${ }^{a}$
}

\begin{abstract}
Background: Liaison critical paths (LCPs) for coronary artery disease $(\mathrm{CAD})$ were developed to support collaborative care for CAD patients between cardiologists in emergency hospitals and referring physicians through sharing of medical information, including cardioprotective medications and cardiovascular risk factors. However, little is known about the effects of LCPs in practice.
\end{abstract}

Methods: We conducted an observational study of CAD patients undergoing percutaneous coronary intervention in our hospital between September 2007 and June 2010; these patients were managed with an LCP by referring physicians after discharge. We surveyed implementation of scheduled hospital visits, prescription of cardioprotective medicines, and risk factor measurements 6 and 12 months after discharge.

Results: Implementation rate of hospital visits was significantly elevated from $50.7 \%$ to $89.3 \%$ after establishing LCPs. At the 12 -month visit, prescription rates for anti-platelet drugs, statins, $\beta$-blockers, and angiotensin-converting enzyme inhibitors or angiotensin II type I receptor blockers were 99.7\%, 95.0\%, 77.1\%,

Manuscript accepted for publication March 6, 2012

\footnotetext{
${ }^{a}$ Department of Cardiology, National Hospital Organization, Kure Medical Center, 3-1 Aoyama-cho, Kure, Hiroshima 737-0023, Japan

${ }^{b}$ Department of Internal Medicine, National Hospital Organization, Kure Medical Center, 3-1 Aoyama-cho, Kure, Hiroshima 737-0023, Japan

${ }^{\mathrm{c}}$ Institute of Clinical Research, National Hospital Organization, Kure Medical Center, 3-1 Aoyama-cho, Kure, Hiroshima 737-0023, Japan

${ }^{\mathrm{d}}$ Corresponding author: Morihiro Matsuda, National Hospital Organization, Kure Medical Center, 3-1 Aoyama-cho, Kure, Hiroshima 737-0023, Japan. Email: morihiro-m@kure-nh.go.jp
}

doi:10.4021/jocmr845w and $74.3 \%$, respectively. Target achievement rates for low-density lipoprotein cholesterol (LDL-C; $<100 \mathrm{mg} / \mathrm{dL}$ ) and high-density lipoprotein cholesterol (HDL-C; $\geq 40 \mathrm{mg} / \mathrm{dL}$ ) significantly increased from $48.6 \%$ to $64.5 \%$ and $62.0 \%$ to $82.7 \%$, respectively, while those for body mass index (BMI; $\left.<25 \mathrm{~kg} / \mathrm{m}^{2}\right)$, blood pressure $(<$ $130 / 80 \mathrm{mmHg})$, triglycerides $(<150 \mathrm{mg} / \mathrm{dL})$, and $\mathrm{HbAlc}(<7.0 \%)$ were unchanged. BMI, triglycerides, HDL-C, LDL-C, and HbA1c levels significantly improved in patients who implemented all visits. Moreover, risk factor management did not differ significantly between cardiologists and non-cardiologists using LCPs.

Conclusions: LCPs for CAD may facilitate implementation of optimal medical therapy and target achievement of risk factors in practice.

Keywords: Liaison critical path; Coronary artery disease; Cardiovascular prevention; Risk factors; Clinical practice

\section{Introduction}

Current guidelines have documented the significance of systemic therapies that reduce plaque vulnerability through evidence-based use of medication and aggressive intervention for multiple cardiovascular risk factors in reducing the rate of death or myocardial infarction [1-3]. The Clinical Outcomes Utilizing Revascularization and Aggressive Drug Evaluation (COURAGE) trial demonstrated that focal therapy with percutaneous coronary intervention (PCI) for stenotic coronary lesions did not reduce the risk of major cardiovascular events when added to optimal medical therapy (OMT) in patients with stable coronary artery disease (CAD). This provides evidence reinforcing current guidelines supporting the aggressive use of OMT [4]. However, in clinical practice, almost a third of patients are not treated with OMT at discharge following PCI, a pattern that has showed little change even after the publication of the COURAGE trial [5]. These findings indicate that improvements are required in the incorporation of OMT into routine practice.

In Japan, elderly people over the age of 65 years accounted for $21 \%$ of the population, the world's highest, in 2005. This percentage increased to $23.2 \%$ in June 2011, and 
Table 1. Baseline Characteristics of the Subjects

\begin{tabular}{|c|c|c|c|}
\hline & Without LCP & With LCP & \multirow{2}{*}{$\mathbf{P}^{\#}$} \\
\hline & (Jan.-Dec. 2006) & (Oct. 2007-Jun. 2010) & \\
\hline Number of patients & 140 & 318 & \\
\hline Age (y) & $70.8 \pm 9.3$ & $69.2 \pm 9.9$ & 0.093 \\
\hline Male (\%) & 66.4 & 74.2 & $0.088^{*}$ \\
\hline \multicolumn{4}{|l|}{ Coronary artery disease } \\
\hline AMI (\%) & 29.3 & 28.9 & $0.939 *$ \\
\hline Others $(\%)$ & 70.7 & 71.1 & \\
\hline BMI $\left(\mathrm{kg} / \mathrm{m}^{2}\right)$ & $23.3 \pm 3.7$ & $24.1 \pm 4.0$ & 0.089 \\
\hline \multicolumn{4}{|l|}{ Blood Pressure } \\
\hline Systolic (mmHg) & $133.4 \pm 25.3$ & $129.4 \pm 20.1$ & 0.058 \\
\hline Diastolic (mmHg) & $72.6 \pm 15.4$ & $72.8 \pm 12.7$ & 0.999 \\
\hline \multicolumn{4}{|l|}{ Laboratory } \\
\hline Triglycerides $(\mathrm{mg} / \mathrm{dL})$ & $118.5 \pm 79.3$ & $125.7 \pm 72.2$ & 0.357 \\
\hline HDL-C (mg/dL) & $44.4 \pm 13.1$ & $44.4 \pm 11.7$ & 0.900 \\
\hline LDL-C (mg/dL) & $100.7 \pm 32.3$ & $104.1 \pm 30.3$ & 0.291 \\
\hline HbA1c $(\%)$ & $6.7 \pm 1.6$ & $6.3 \pm 1.3$ & $<0.001$ \\
\hline
\end{tabular}

\# Statistical analyses were performed by Student's t-test or chi-square test (*). LCP, liaison critical path; AMI, acute myocardial infarction; BMI, body mass index; HDL-C, high-density lipoprotein cholesterol; LDL-C, low density lipoprotein cholesterol.

is expected to rise further in the future [6]. To reduce the load on physicians in emergency hospitals, the government has recommended the development of local collaborations between emergency hospitals and general clinics since 2006 . According to this policy, recently stabilized patients with $\mathrm{CAD}$ tend to be managed by referring primary physicians; however, these doctors are not always familiar with recent evidence for cardiovascular prevention. To resolve this social issue, liaison critical paths (LCPs) for the management of CAD have been developed. Generally, in the LCP system, cardiologists in emergency hospitals and referring physicians cooperatively manage CAD patients using an information tool, i.e., printed information sheets or electronic files on the internet, to share medical information, including severity of CAD, coronary intervention, medications, cardiovascular risk factors, guideline-based targets for the control of risk factors, and schedules of follow-up examinations. Our hos- pital is in Kure City, where the elderly account for $28.2 \%$ of the population [7]; this was Japan's highest elderly ratio in cities with a population of over 150,000 people in 2010 . A hospital-based LCP system for CAD has been established in our hospital since 2007. Recently, in many medical areas, public health centers or medical associations have developed community-based LCPs for CAD, although the management systems and/or information tools are somewhat different among medical areas. However, little is known about the clinical benefits of LCP in practice.

To assess whether LCP for CAD may have the potential to facilitate the implementation of OMT, we surveyed the implementation rate of scheduled hospital visits, the prescription rate of cardioprotective medications, and the achievement rate of guideline targets for risk factors in patients managed with LCP for CAD before discharge and during 1 year of observation. In addition, we compared the 
Table 2. Implementation of Follow-up Hospital Visits With or Without Liaison Critical Path

\begin{tabular}{llll}
\hline & Without LCP & With LCP & P $^{\#}$ \\
\cline { 2 - 3 } & (Jan.-Dec. 2006) & (Oct. 2007-Jun. 2010) & $<0.001$ \\
\hline Total subjects, $\mathrm{n}$ & 140 & 318 & $280(88.1)$ \\
6-month visit, n (\%) & $75(53.6)$ & & $<0.001$ \\
\hline
\end{tabular}

\# Statistical analyses were performed by chi-square test. LCP, liaison critical path.

management of risk factors by referring physicians using the LCP system between cardiologists and non-cardiologists.

\section{Methods}

\section{Management system using liaison critical path for CAD}

We established an LCP system for the management of patients with CAD in routine practice. This system was introduced to all patients with CAD undergoing PCI who received outpatient treatment in general clinics after discharge. Using this system, all patients received multidisciplinary education on preventing cardiovascular events before discharge, including information on their cardiovascular risk factors, the purpose and effects of their medication, and how to change their lifestyle, i.e., how to make healthy food choices and do suitable exercise. All of this information was described on the LCP information sheet. Furthermore, the LCP information sheet provided each patient's personal medical information to referring physicians in general clinics, including severity of CAD, coronary intervention, medications, car-

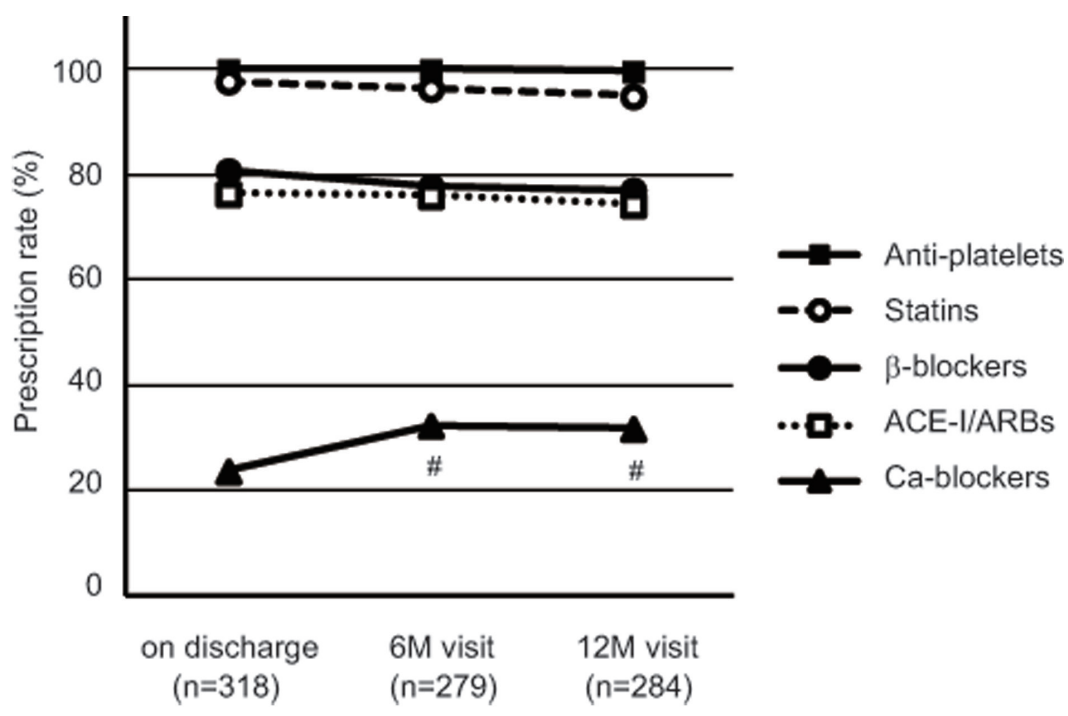

Figure 1. Prescription of several classes of cardioprotective medicines in clinical practice with liaison critical path. Proportions of the patients who were prescribed anti-platelet agents, statins, $\beta$-blockers, angiotensin-converting enzyme inhibitors (ACE-Is)/angiotensin II type I receptor blockers (ARBs), and calcium channel $(\mathrm{Ca})$ blockers are shown at indicated times. Six-month $(6 \mathrm{M})$ and 12 -month $(12 \mathrm{M})$ visits were scheduled at $6 \pm 3$ months and $12 \pm 3$ months after hospital discharge, respectively. Statistical analyses were performed by chi-square test. \#: $\mathrm{P}<0.05$ vs. on discharge. 


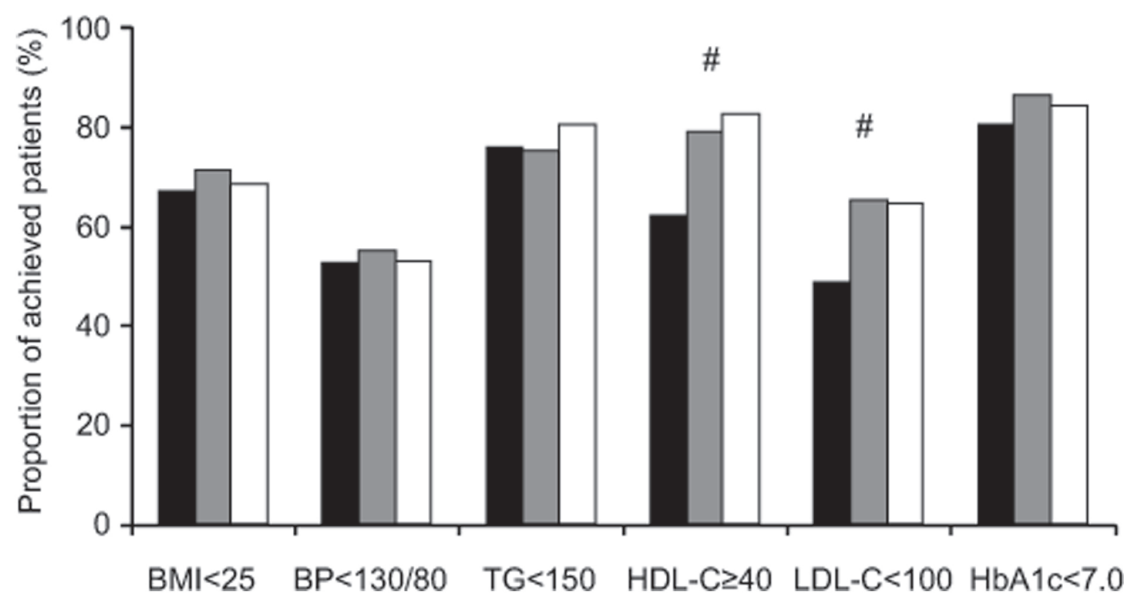

Figure 2. Achievement rates of guideline targets for cardiovascular risk factors in clinical practice with liaison critical path. Proportions of the patients who achieved body mass index $(\mathrm{BMI})<25 \mathrm{~kg} / \mathrm{m}^{2}$, blood pressure $(\mathrm{BP})<130 / 80 \mathrm{mmHg}$, triglycerides $(\mathrm{TG})<150 \mathrm{mg} / \mathrm{dL}, \mathrm{HbA} 1 \mathrm{c}<7.0 \%$, low density lipoprotein cholesterol (LDL-C) $<100 \mathrm{mg} / \mathrm{dL}$, and high density lipoprotein cholesterol $(\mathrm{HDL}-\mathrm{C}) \geq 40 \mathrm{mg} / \mathrm{dL}$ are shown at indicated times. Six-month $(6 \mathrm{M})$ and 12 -month (12M) visits were scheduled at $6 \pm 3$ months and $12 \pm 3$ months after hospital discharge, respectively. Statistical analyses were performed by chi-square test. \#: $\mathrm{P}<0.05$ vs. before discharge.

diovascular risk factors, the guideline targets for risk factors, and schedules of follow-up examinations in our hospital. Official staff assigned to local clinical liaison sent a list of patients to referring physicians by fax or e-mail to remind them which patients were scheduled to visit our hospital before the scheduled follow-up date. Trained nurses explained the follow-up examinations to patients before the scheduled date by phone. Referring physicians marked checkboxes indicating achievement of guideline targets for each risk factor on the LCP information sheet. In cases where referring physicians suspected progression of angina pectoris or occurrence of cardiac events, they could immediately consult cardiologists in our hospital at any time. Cardiologists in our hospital provided information on the results of followup examinations and suggestions for suitable medications to referring physicians.

\section{Subjects and data collection}

The subjects in this study were a consecutive series of 318 patients with CAD undergoing PCI from September 2007 to June 2010 who received outpatient treatment in general clinics with LCP after discharge. In addition, as a control, we surveyed 140 consecutive patients with CAD undergoing PCI from January to December in 2006 who received outpatient treatment in general clinics before the establishment of LCP. The data were collected by retrospectively reviewing all individual medical records during hospitalization and follow-up visits. The first and second visits were scheduled at $6 \pm 3$ months and $12 \pm 3$ months after hospital discharge, respectively. The data collected included body mass index
(BMI), blood pressure, prescription of several classes of medicines including anti-platelet agents, statins, $\beta$-blockers, angiotensin-converting enzyme inhibitors (ACE-Is) or angiotensin II type I receptor blockers (ARBs), and calcium channel blockers (CCBs), and circulating levels of various parameters including total cholesterol, triglycerides, highdensity lipoprotein cholesterol (HDL-C), low-density lipoprotein cholesterol (LDL-C), and HbAlc. This study was approved by the Ethics Committee of Kure Medical Center.

\section{Laboratory measurements}

Venous blood was drawn from all of the subjects after an overnight fast. The serum was immediately subjected to laboratory measurements. Serum concentrations of total cholesterol, triglycerides, and HDL-C were determined by enzymatic methods (Sekisui Medical Co., Tokyo). The concentration of HbA1c (JDS: Japan Diabetic Society) was measured by high performance liquid chromatography (TOSOH Co., Tokyo) and then was calculated as HbAlc (NGSP: National Glycohemoglobin Standardization Program) [8]. LDL-C was calculated by the Friedewald formula.

\section{Achievement of guideline targets for cardiovascular risk factors}

We used the following targets for management of cardiovascular risk factors in patients with $\mathrm{CAD}$, according to Japanese guidelines [2, 3, 8-11]: BMI $<25 \mathrm{~kg} / \mathrm{m}^{2}$, blood pressure $<130 / 80 \mathrm{mmHg}$, triglycerides $<150 \mathrm{mg} / \mathrm{dL}, \mathrm{HbAlc}$ (NGSP) $<7.0 \%$, LDL-C $<100 \mathrm{mg} / \mathrm{dL}$, and HDL-C $\geq 40 \mathrm{mg} / \mathrm{dL}$. 

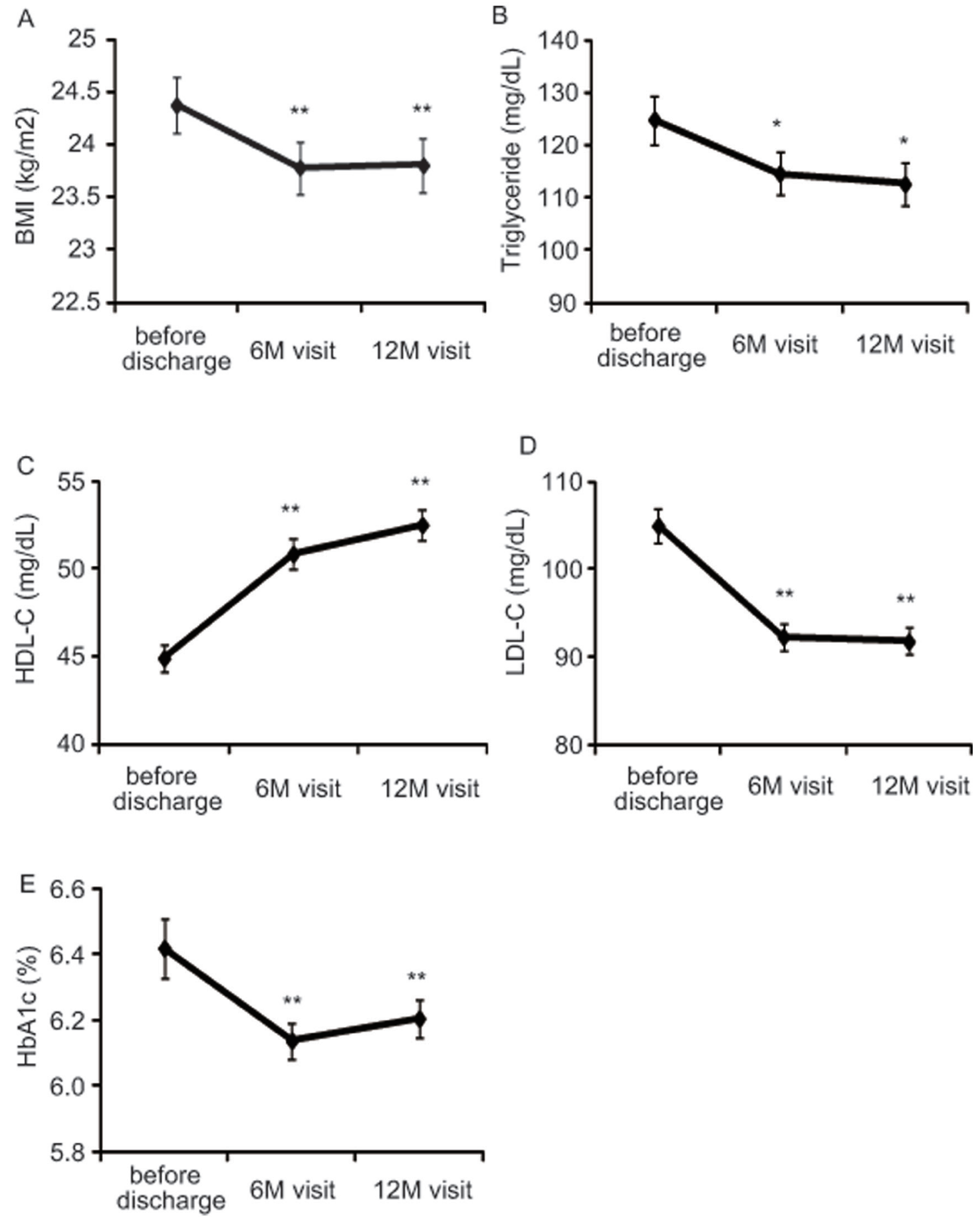

Figure 3. Changes of several parameters associated with risk factors in clinical practice with liaison critical path. Body mass index $(\mathrm{BMI})\left(\mathrm{kg} / \mathrm{m}^{2}\right)(\mathrm{A})$, triglycerides $(\mathrm{mg} / \mathrm{dL})(B)$, high density lipoprotein cholesterol $(\mathrm{HDL}-\mathrm{C})(\mathrm{mg} / \mathrm{dL})(\mathrm{C})$, low density lipoprotein cholesterol LDL-C (mg/dL) (D), and HbA1c (\%) (E) are shown at indicated times. Six-month (6M) and 12-month $(12 \mathrm{M})$ visits were scheduled at $6 \pm 3$ months and $12 \pm 3$ months after hospital discharge, respectively. Data are expressed as mean \pm SEM. Statistical analyses were performed by paired t-test. ${ }^{* *}$ : $P<0.001,{ }^{*}: P<0.01$ vs. before discharge.

\section{Statistical analysis}

Data are expressed as mean \pm SEM. Paired t-tests were performed to evaluate changes in various parameters after hospital discharge. The chi-square test was performed to assess implementation of scheduled visits, cardioprotective 
Table 3. Management of Coronary Artery Disease Patients by Cardiologists and Non-Cardiologists With Liaison Critical Path

\begin{tabular}{|c|c|c|c|}
\hline & Cardiologist & Non-cardiologist & \multirow{2}{*}{$\mathbf{P}^{\#}$} \\
\hline & $(n=45)$ & $(n=74)$ & \\
\hline \multicolumn{4}{|l|}{ Implementation of scheduled visit } \\
\hline 6-month visit, (\%) & 86.2 & 89.4 & 0.386 \\
\hline 12-month visit, $(\%)$ & 85.4 & 92.0 & 0.060 \\
\hline \multicolumn{4}{|l|}{ Achievement of targets (12-month) } \\
\hline $\mathrm{BMI}<25 \mathrm{~kg} / \mathrm{m}^{2},(\%)$ & 72.1 & 66.3 & 0.307 \\
\hline Blood pressure $<130 / 80 \mathrm{mmHg},(\%)$ & 51.4 & 55.7 & 0.482 \\
\hline Triglycerides $<150 \mathrm{mg} / \mathrm{dL},(\%)$ & 80.0 & 80.8 & 0.865 \\
\hline HDL-C $\geq 40 \mathrm{mg} / \mathrm{dL},(\%)$ & 80.8 & 83.9 & 0.503 \\
\hline LDL-C < 100 mg/dL, (\%) & 69.2 & 61.3 & 0.185 \\
\hline $\mathrm{HbA} 1 \mathrm{c}<7.0 \%,(\%)$ & 88.8 & 81.8 & 0.123 \\
\hline
\end{tabular}

\# Statistical analyses were performed by chi-square test. BMI, body mass index; HDL-C, high-density lipoprotein cholesterol; LDL-C, low density lipoprotein cholesterol.

medications, achievement of guideline targets for risk factors, and comparison of medical management between cardiologists and non-cardiologists. All statistical analyses were performed using JMP for Windows software (version 8; SAS Institute, Cary, NC). Statistical significance was defined as a $\mathrm{P}$ value of $<0.05$.

\section{Results}

Implementation of scheduled follow-up visits after hospital discharge

There was no significant difference in the baseline characteristics of the patients between before and after establishment of LCP, except HbAlc (Table 1). Table 2 shows the proportion of patients who implemented the hospital visits scheduled at 6 and 12 months after discharge, which significantly increased from $50.7 \%$ to $89.3 \%$ after establishing LCP.

Among the patients managed with LCP, $10.7 \%$ did not visit our hospital at 12 months after discharge, which included the $6.6 \%$ of patients who gave up the scheduled hospi- tal visits for unavoidable reasons, such as death, muscular neurological disorders, and advanced cancers. Only $4.1 \%$ of patients did not implement scheduled visits for other reasons, such as low compliance (data not shown).

\section{Cardioprotective medications in clinical practice with LCP}

Initial prescription rates for anti-platelet agents, statins, $\beta$-blockers, and ACE-Is or ARBs were very high $(100.0 \%$, $97.8 \%, 80.8 \%$, and $76.4 \%$ on discharge, respectively). This high prescription rate was maintained during the follow-up period $(99.7 \%, 95.0 \%, 77.1 \%$, and $74.3 \%$ at the 12 -month visit, respectively; Fig. 1). The prescription rate for CCBs increased from $23.6 \%$ on discharge to $32.3 \%$ and $31.7 \%$ at the 6- and 12 -month visits, respectively (both $\mathrm{P}<0.05$ vs. on discharge; Fig. 1).

\section{Achievement of guideline targets for risk factors in clini- cal practice with LCP}

The achievement rate for LDL-C $<100 \mathrm{mg} / \mathrm{dL}$ showed a sig- 
nificant increase from $48.6 \%$ before discharge to $64.5 \%$ at the 12-month visit $(\mathrm{P}<0.05)$, and that for HDL-C $\geq 40 \mathrm{mg} /$ $\mathrm{dL}$ also significantly increased from $62.0 \%$ before discharge to $82.7 \%$ at the 12 -month visit $(\mathrm{P}<0.05$; Fig. 2$)$. Achievement rates for triglycerides $<150 \mathrm{mg} / \mathrm{dL}$ and $\mathrm{HbA} 1 \mathrm{c}<7.0 \%$ were $80.5 \%$ and $84.5 \%$ at the 12 -month visit, respectively; these rates were high before discharge and were maintained over 1 year (Fig. 2). On the other hand, the achievement rates for BMI $<25 \mathrm{~kg} / \mathrm{m}^{2}$ and blood pressure $<130 / 80 \mathrm{mmHg}$ were $68.6 \%$ and $53.1 \%$ at the 12 -month visit; these rates were not improved during 1 year of observation (Fig. 2).

\section{Control of cardiovascular risk factors in clinical practice with LCP}

In the patients who implemented all visits, BMI, LDL-C, HDL-C, and triglyceride levels were significantly improved over the follow-up period (BMI, $\mathrm{P}<0.001$; LDL-C, $\mathrm{P}<$ 0.001; HDL-C, $\mathrm{P}<0.001$; triglycerides, $\mathrm{P}<0.01$; Fig. 3 ). $\mathrm{HbA1c}$ significantly decreased at the 6-month visit $(\mathrm{P}<$ 0.05 ), but this was slightly reversed at the 12 -month visit (Fig. 3).

\section{Management of CAD patients with LCP by cardiologists and non-cardiologists}

Next, we compared the management of CAD patients with LCP by referring physicians between cardiologists and noncardiologists. As shown in Table 3, there was no significant difference in the proportion of patients who visited our hospital for follow-up according to the LCP schedule between those treated by cardiologists and those treated by non-cardiologists. Moreover, the achievement rates of the guideline targets for risk factors at the 12-month visit did not differ significantly between cardiologists and non-cardiologists (Table 3).

\section{Discussion}

Our study demonstrates that the proportion of patients implementing follow-up hospital visits was significantly elevated after development of an LCP system. The prescription rates of cardioprotective medicines including anti-platelet agents, statins, ACE-Is or ARBs, and $\beta$-blockers were very high on discharge after PCI, and these rates were maintained over 1 year. The proportion of patients who achieved a LDL-C level $<100 \mathrm{mg} / \mathrm{dL}$ and a HDL-C level $\geq 40 \mathrm{mg} / \mathrm{dL}$ was significantly elevated during 1 year of observation. BMI, triglycerides, HDL-C, LDL-C, and HbAlc were significantly improved in the patients who implemented all visits scheduled by the LCP. Moreover, our study demonstrated that there was no significant difference in the management of CAD patients between cardiologists and non-cardiologists when using
LCP, suggesting that LCP may be an effective way to bridge the gap between published evidence-based guidelines and routine clinical practice.

Despite the establishment of evidence-based guidelines, prevention therapies are sometimes underused in daily clinical practice [5, 12-14]. Borden, et al. reported that even after the publication of the COURAGE trial, prescription rates of statins, ACE-Is or ARBs, and $\beta$-blockers were 84.7\%, $60.7 \%$, and $75.9 \%$, respectively, for patients after PCI [5]. In our study, the prescription rates of these medicines were $95.0 \%, 74.3 \%$, and $77.1 \%$ at 1 year after PCI, respectively, in patients treated by general primary physicians with LCP. This suggests that the LCP system may support general primary physicians to facilitate the implementation of evidencebased medication for cardiovascular prevention.

During clinical practice by Japanese general physicians, the achievement rates of guideline targets for LDL-C and systolic blood pressure have been reported to be $57.1 \%$ and $34.0 \%$, respectively, although the subjects in this study included patients without CAD [15]. In our survey, subjects managed with LCP showed relatively higher achievement rates of guideline targets; those for LDL-C and blood pressure were $64.5 \%, 53.1 \%$, respectively. This suggests that the LCP system may increase the opportunity for general primary physicians to develop their awareness of the achievement of guideline targets. Patients who achieve guideline targets show significantly less cardiovascular events than those who do not [15]. Therefore, it can be expected that the LCP system used in the current study may be effective for suppression of cardiovascular events, although we did not investigate cardiovascular events directly.

Thus, the LCP system used seems to be effective in the implementation of guideline-based strategies for cardiovascular prevention. This may be not only due to sharing of medical information between emergency hospitals and general clinics but also due to the multidisciplinary education on cardiovascular prevention received by the patients. Such education helps patients to understand the significance of controlling their cardiovascular risk factors, learn about the purpose and effects of their medication, and be more motivated to change their lifestyle. In addition, another essential component of the LCP system used may be the reminders for follow-up hospital visits sent to both the referring physicians and the patients before scheduled examinations. In turn, this LCP system should increase the opportunity for cardiologists who are aware of up-to-date evidence to conduct optimal medical control of risk factors.

Nevertheless, in our study, the continuous control of body weight, blood pressure, and diabetes seemed to be difficult even when using the LCP system, which suggests that continuing a healthy life-style is more difficult for patients than merely starting one. Our LCP system seems to be less effective for continuous improvements in lifestyle for patients. Another system is required to continuously motivate 
patients to maintain a healthy life-style.

Our study provides suggestive data on the effects of LCP but not conclusive evidence, as it was an observational study based on retrospective investigation of medical records in a single center. To further investigate the effectiveness of LCP systems, including effects on prevention of cardiovascular events, multi-center prospective studies with larger samples are required.

We live in an aged society, where even high-risk patients should be managed in practice by general physicians, rather than cardiologists. In addition, implementation of evidencebased cardiovascular prevention strategies in practice is becoming more important. Our data suggest that LCP for CAD may have the potential to facilitate implementation of evidence-based medicine in practice, although further investigations are required.

\section{Acknowledgement}

We thank Noriko Okamoto for supporting the collection of medical records. We thank all nurses, nutritionists, pharmacists and physical therapists for education of patients, and official staffs in the division of clinical liaison for keeping in contact with referring physicians. We thank all the referring physicians in Kure for supporting our LCP system.

\section{Conflict of Interest}

None.

\section{References}

1. Smith SC, Jr., Allen J, Blair SN, Bonow RO, Brass LM, Fonarow GC, Grundy SM, et al. AHA/ACC guidelines for secondary prevention for patients with coronary and other atherosclerotic vascular disease: 2006 update: endorsed by the National Heart, Lung, and Blood Institute. Circulation. 2006;113(19):2363-2372.

2. Ogihara T, Kikuchi K, Matsuoka H, Fujita T, Higaki J, Horiuchi M, Imai Y, et al. The Japanese Society of Hypertension Guidelines for the Management of Hypertension (JSH 2009). Hypertension research : official journal of the Japanese Society of Hypertension. 2009;32(1):3-107.

3. [Japan Atherosclerosis Society (JAS) guidelines for prevention of atherosclerotic cardiovascular diseases]. Journal of atherosclerosis and thrombosis. 2007:5-57.

4. Boden WE, O'Rourke RA, Teo KK, Hartigan PM, Maron DJ, Kostuk WJ, Knudtson M, et al. Optimal medical therapy with or without PCI for stable coronary disease. The New England journal of medicine. 2007;356(15):1503-1516.
5. Borden WB, Redberg RF, Mushlin AI, Dai D, Kaltenbach LA, Spertus JA. Patterns and intensity of medical therapy in patients undergoing percutaneous coronary intervention. JAMA : the journal of the American Medical Association. 2011;305(18):1882-1889.

6. Population Estimates by Age (5 Year Age Group) and Sex - June 1, 2011(Final estimates). Population Census Division, Statistical Survey Department, Statistics Bureau, Ministry of Internal Affairs and Communications, Japan. 2011. Available from: http:/www.stat.go.jp/english/data/jinsui/tsuki/index.htm.

7. Basic Residential Registries in 2010. Residents Administration Policy and Management Division, Local Administration Bureau, Ministry of Internal Affairs and Communications, Japan. 2010. Available from: http:// www.soumu.go.jp/main_sosiki/jichi_gyousei/daityo/ gaiyou.html.

8. The committee of Japan Diabetes Society on the Diagnostic Criteria of Diabetes Mellitus. Report of the committee on the classification and diagnostic criteria of diabetes mellitus. J Diabetes Invest 2010; 1:212-228.

9. Chin R, Miyazaki S. [Criteria of obesity and obesity disease in Japan]. Nihon rinsho. Japanese journal of clinical medicine. 2009;67(2):297-300.

10. Teramoto T, Sasaki J, Ueshima H, Egusa G, Kinoshita M, Shimamoto K, Daida H, et al. Metabolic syndrome. Journal of atherosclerosis and thrombosis. 2008;15(1):1-5.

11. The Guidelines for the Diagnosis and Treatment of Cardiovascular Diseases (The Joint Study Group 2010). Guidelines for secondary prevention of myocardial infarction. (Japan Circulation Society 2011).

12. Javed U, Deedwania PC, Bhatt DL, Cannon CP, Dai D, Hernandez AF, Peterson ED, et al. Use of intensive lipid-lowering therapy in patients hospitalized with acute coronary syndrome: an analysis of 65,396 hospitalizations from 344 hospitals participating in Get With The Guidelines (GWTG). American heart journal. 2010;160(6):1130-1136, 1136 e1131-1133.

13. Melloni C, Shah BR, Ou FS, Roe MT, Smith SC, Jr., Pollack CV, Jr., Ohman M, et al. Lipid-lowering intensification and low-density lipoprotein cholesterol achievement from hospital admission to 1-year followup after an acute coronary syndrome event: results from the Medications ApplIed aNd SusTAINed Over Time (MAINTAIN) registry. American heart journal. 2010;160(6):1121-1129, 1129 e1121.

14. Webster RJ, Heeley EL, Peiris DP, Bayram C, Cass A, Patel AA. Gaps in cardiovascular disease risk management in Australian general practice. The Medical journal of Australia. 2009;191(6):324-329.

15. Current trends in lifestyle-related disease management by general practitioners: a report from the "Heart Care Network" groups. Journal of atherosclerosis and thrombosis. 2009;16(6):799-806. 